\title{
Breve análise da peça teatral incompleta de Hölderlin, “A morte de Empédocles”
}

\author{
Short analysis of Hölderlin's incomplete \\ theater, "The death of Empedocles"
}

Rafael César Pitt ${ }^{1}$

\begin{abstract}
1 Professor do Curso de Filosofia da Unifap - Campus Santana, Brasil.
E-mail: rafaelpittunifap@gmail.com Orcid: http://orcid.org/0000-0003-4045-6574
\end{abstract}

RESUMO: O tema deste artigo é o insucesso da produção teatral do poeta suábio Friedrich Hölderlin na confecção de "A morte de Empédocles". O objetivo é apontar a crescente ausência de indicações cênicas e elementos de representação entre as três versões inacabadas da obra (1797-1800). Para tal comentaremos diversos instantes do objeto analisado nos quais transparecem ora caracteres filosóficos, ora caracteres poéticos e também teatrais, com indicações do abandono da teatralidade e do ambiente cênico em favorecimento da poesia e de uma visão mítica da personagem principal. Nosso fundamento teórico será composto por alguns autores que consideram o desenvolvimento histórico da obra de Hölderlin enquanto poeta do século XVIII. Os resultados alcançados indicam que a constante revisão da peça teatral deveu-se às mudanças de concepção sobre o sentido da tragédia como conceito, não tendo o autor conseguido transpor para o texto cênico a quintessência de sua ideia criadora. A conclusão a que chegamos indica que Hölderlin não atende ao escopo da tragédia como expressão teatral no sentido aristotélico porque seu personagem principal supera a dicotomia que está na base de toda obra trágica: o conflito entre o indivíduo livre e seu tempo obscuro, sua cultura decaída, seu destino fatídico. Empédocles vira um mito.

Palavras-chave: Hölderlin; Empédocles; tragédia.

ABSTRACT: The subject of this article is the failure of the theatrical production of the Swabian poet Friedrich Hölderlin in the making of "The Death of Empedocles". The objective is to point out the growing absence of scenic indications and elements of representation between the three unfinished versions of the work (1797-1800). For this we will comment several moments of the object analyzed in which sometimes appear philosophical characters, sometimes poetic and also theatrical characters, with indications of the abandonment of theatricality and the scenic environment in favor of poetry and a mythical view of the main character. Our theoretical foundation will be composed of some authors who consider the historical development of Hölderlin's work as an eighteenth-century poet. The results achieved indicate that the constant revision of the play was due to changes in the conception of the meaning of tragedy as a concept, and the author was unable to transpose the quintessence of his creative idea into the scenic text. The conclusion we reach indicates that Hölderlin does not address the scope of tragedy as a theatrical expression in the Aristotelian sense because his main character overcomes the dichotomy that underlies all tragic work: the conflict between the free individual and his dark time, his fallen culture. , your fateful destiny. Empedocles becomes a myth.

Keywords: Hölderlin; Empedocles; tragedy.

\section{Introdução}

Johann Christian Friedrich Hölderlin nasceu a vinte de março de 1770 em Lauffen, região da Suábia. Aos 
quatorze anos frequentou o convento preparatório em Denkendorf e durante os anos de 1786-8 esteve no colégio religioso superior de Maulbronn. Suas primeiras leituras e poesias datam deste período, contudo foi no estudo de teologia de Tubingen, entre 1788-93, que o jovem rapaz iria receber forte formação humanística e definir alguns de seus traços definitivos ao lado de Hegel e Schelling. Apesar de estar presente na formação inicial do idealismo alemão, Hölderlin não segue esta linha exaustivamente. Sua obra é bem diversificada e dialoga igualmente com o Romantismo, por exemplo, além de conservar aspectos originais que destoam de seus círculos culturais contemporâneos. Ao longo de sua vida produziu principalmente poesia, mas também romance e teatro.

De certa forma Hölderlin busca realizar na poesia e na peça aqui analisada o ideal romântico de união do antigo espírito grego com o moderno espírito alemão. Aquele seria uma espécie de panaceia já que era imbuído de amor e união entre o humano e a natureza enquanto este era cindido pela técnica e pelo distanciamento entre as pessoas. Esta junção espiritual seria obra dos poetas e filósofos que decidissem realizar na Alemanha a grandeza e o esplendor da Antiguidade e, para tal, precisavam de um ponto de ligação entre "os dois mundos". É aqui que entra o filósofo grego Empédocles de Agrigento.

A historiografia das ideias filosóficas no mundo antigo foi feita sobre tradições orais pouco afeitas ao que hodiernamente é chamado de "objetividade". Relatos considerando a fama ou a popularidade de certa figura, assim como feitos notáveis transmitidos por anônimos foram registrados e tidos como "fatos observáveis". É este tipo de informação que encontramos na obra de Diógenes Laércio, Vida e doutrina dos filósofos ilustres (3 d.C.). Ali está escrito algo sobre Empédocles e que perdurou como mito(?)/lenda(?) pela tradição ocidental, a saber, que Empédocles não era humano, e sim um deus, e que sua morte não teria sido natural e sim voluntária, jogando-se nas chamas do Monte Etna a fim de retornar à unidade profunda com a natureza.

Esta versão incrível sobre o fim da vida do filósofo grego se tornou um tema literário e foi apropriado por Hölderlin da seguinte maneira: Empédocles é a encarnação da unidade espiritual antiga. Sua vida e morte unem de forma perfeita a condição terrena e a divindade diluída no cosmos. Em termos teatrais, ele é o herói que encerra em seu exemplo a possibilidade de superação da cisão que define a comunidade a sua volta. Foi com este pensamento que Hölderlin assume para si a missão que escrever uma peça teatral que serviria para seus pares como uma produção artística que contém, na sua contemporaneidade, o resgate daquela unidade perdida na antiguidade. Porém, as condições práticas de redação da peça sofreram reviravoltas inesperadas e, como veremos, a elaboração temática da mesma não atinge os objetivos propostos. Em que pesem os esforços do autor - tal como discutiremos ao final do artigo - o modelo de ação teatral adotado - a tragédia aristotélica exige algumas regras de confecção para produzir o efeito poético almejado.

\section{A peça - $1^{a}$ versão}

A primeira cena do primeiro ato é formada pelo diálogo entre Panteia e Délia. Panteia é a filha do rei Crítias que conhece pessoalmente Empédocles e possui grande admiração por ele devido à cura que o mesmo aplicara nela, livrando-a de grande sofrimento. Délia, por sua vez, estivera na Sićlia na infância e de retorno agora. Naquele tempo presenciara Empédocles na auriga durante os jogos Olímpicos e se lembra da grande fama deste nome. Ambas estão conversando sobre ele por ocasião, justamente, da chegada de Délia às terras italianas. A indicação cênica é feita pela própria quando diz "se só ontem cheguei com meu pai, à Sicília” (HÖLDERLIN, 2008, p. 85). 
Nesta primeira versão da peça percebemos uma maior humanização dos conflitos vivenciados dentro da intriga e uma menor divinização do personagem Empédocles. A cura da doença de Panteia é um elemento demasiadamente humanizante das personagens. Qualquer pessoa se sentiria grata a quem lhe retornou a saúde. Neste contexto de admiração e de apresentação do grande médico, Panteia usa uma descrição mítica para se referir a ele, porém, tais adjetivações são mais fáceis de serem vistas como elogios movidos a gratidão do que como narração factual. Diz ela sobre Empédocles - evocando poderes do mito de Orfeu para apaziguar as potências da natureza:

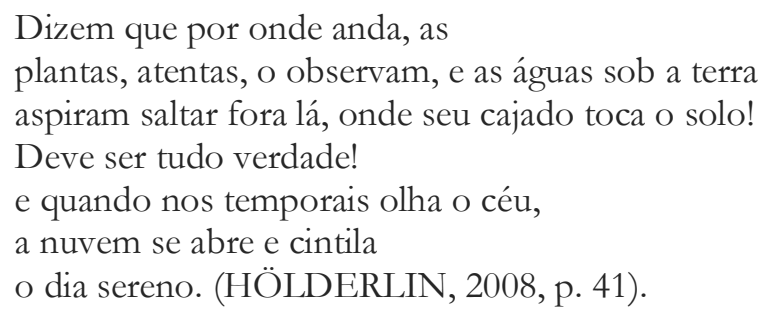

O tom de apresentação do protagonista presente na fala de Panteia não se dirige somente a Délia, mas também ao público que estivesse presente na encenação. E como ao público precisa ser apresentado o mínimo de pontos que compõe a trama, Panteia prossegue em seu discurso de abertura evocando mais três personagens fundamentais para o enredo: Hermócrates, o sacerdote arconte antagonista a Empédocles; os concidadãos agrigentinos que farão papel próximo ao que o coro desempenhava no teatro clássico, e Pausânias, melhor amigo do protagonista e confidente das verdadeiras motivações do herói.

Sobre Hermócrates é importante frisar sua característica antagônica e hipócrita. Enquanto Empédocles é o filósofo-rei, o basileus, o comungante do divino e deus entre os mortais, aquele é o senso comum autoproclamado sábio, o sacerdote preso a tradições estáticas, o sofista cambaleante de ocasião. A hipocrisia de tal antagonista é expressa logo pela filha do rei que, acamada e à beira da desgraça, é curada por Empédocles a pedido de Crítias. Ou seja, Hermócrates (enquanto amigo do rei Crítias) sabe do pedido de socorro feito pelo governante ao médico taumaturgo, porém Hermócrates (enquanto sacerdote e homem público) não reconhece os dons maravilhosos do herói e, por isso, o acusa de sacrílego e se põe contra ele.

O conjunto de cidadãos de Agrigento sem identidade e uníssonos em relação a Empédocles faz o papel de coro. Portanto, quando se pronunciam, o fazem em conjunto de vozes e posição. Empédocles, todavia, caminha entre eles de forma elíptica, ora se aproximando para instruí-los e auxiliá-los - expressando sua amorosidade divina e seu acolhimento pelos mortais -, ora se afastando para não se imiscuir em suas vidas terrenas - expressando sua necessidade de recolhimento na natureza e entre iguais (os deuses). Este caráter ambíguo da relação entre o personagem principal e o coro se manterá até o final.

Pausânias, por sua vez, é o melhor amigo, discípulo e confidente de Empédocles. Pausânias sabe tudo sobre ele, ainda assim se surpreenderá quando descobrir a decisão do sábio de se jogar no vulcão. De qualquer forma nutre fidelidade e é recebido como um amigo especial do filósofo, sendo muitas vezes exposto como um sujeito excelente e acima da média.

Como a peça é centrada n’a morte de Empédocles, Panteia anuncia que na última vez que o viu detectou uma 'nostalgia estranha', 'uma dor profunda, peculiar', e que por isto o mesmo 'não durarás muito mais’. O que a personagem está anunciando - e que o público deve captar com atenção - é que a peça começa, por assim dizer, às vésperas da morte do personagem principal, e são os conflitos e angústias moventes desta morte a tela sobre a qual será pintada a tragédia. 
A primeira cena termina com a indicação cênica de Délia sobre a aproximação de Hermócrates e Crítias que, com certeza, ficariam constrangidos em ver a princesa próxima aos arredores onde pode-se encontrar Empédocles. Por isso Panteia logo responde: "Vem! Vamos embora!” (HÖLDERLIN, 2008, p. 95).

A próxima cena é o diálogo entre Hermócrates e Crítias. Este é pai de Panteia e anfitrião de Délia. Crítias representa a racionalidade fria e abstrata de alguns filósofos que não reconhecem as potências sagradas por trás de cada fenômeno. Como rei possui todas as condições de intervir a favor de Empédocles e por fim ao litígio que aflige a cidade, contudo ele próprio se amortiza em relação ao mago por ocasião da cura milagrosa da filha que, é sabido, elevou Empédocles aos olhos dos presentes e, consequentemente, diminui a imagem do rei que não pode salvar nem sua própria descendente. "Senti-me, eu mesmo, profundamente envergonhado diante dele quando salvou minha filha da morte." (HÖLDERLIN, 2008, p. 99).

A conversa entre eles expõe o restante de elementos necessários para compor a trama da peça. Falam sobre como a rotina dos ritos e celebrações religiosas da cidade foi perturbada pela declaração polêmica de Empédocles. Desde o dia em que ele disse ser um 'deus entre mortais' os concidadãos ficaram agitados e divididos sobre o assunto. Entre fascinados e horrorizados ninguém conseguiu retornar às velhas crenças e práticas de antes e simplesmente ignorar o basileus que caminhava entre eles.

O povo está tão inebriado, como ele próprio.

Não atendem às leis, a nenhum perigo,

A juiz algum; os costumes,

Como as praias pacíficas, estão

Submersos pelo tumulto revolto. (HÖLDERLIN, 2008, p. 99).

Hermócrates é o mais incomodado com a situação. De fato a situação para ele é insustentável porque a verdade e a dignidade de Empédocles destacam a mentira e a leviandade dele, e seu plano não é nada menos que a expulsão do médico da cidade. Todavia, a simples exclusão da pessoa física não é suficiente. É preciso também destruir a imagem divina inspirada na população para que a cidade retorne à sua normalidade e o poder do sacerdote seja plenamente restituído sobre os cidadãos.

A execução deste plano não pode ter falhas, como bem pondera Crítias, pois se o povo se mantiver ao lado de Empédocles a gravidade do conflito os obrigará a se retirar da cidade! Mas Hermócrates está convencido de que a pecha de ímpio cairá sobre o mago quando a população ouvir a acusação, ou seja, Hermócrates está disposto a usar de toda sua perfídia retórica para aniquilar a boa imagem entorno do filósofo. E como primeira parte do plano é preciso construir uma situação na qual o povo assista ao discurso acusatório do sacerdote. Para tal o antagonista já havia começado a agir e, no dia anterior, pediu aos agrigentinos que permanecessem em casa.

Neste ponto da peça chegamos ao final da segunda cena com duas indicações dos personagens. A primeira é a declaração do sacerdote de que fez o referido pedido de recolhimento aos cidadãos e de que eles “obedeceram. Não há ninguém aqui” (HÖLDERLIN, 2008, p. 103). A segunda é feita por Crítias que, semelhante à Délia ao final da primeira cena, alerta para a chegada de alguém indesejado. No caso é Empédocles que se aproxima ao que Hermócrates responde ao rei: "Vamos, Crítias! Que não nos envolva em seu discurso!" (HÖLDERLIN, 2008, p. 103).

A terceira cena é composta de apenas uma fala solitária de Empédocles. É o momento de apresentação do herói e de sua índole. As palavras saem de sua boca em tom de lamento e se dirigem às 'forças do 
alto', às 'Fontes da Vida', ao 'Éter', à 'Natureza'. A personagem expressa seu queixume de ter perdido o contato íntimo com a divindade (o entusiasmo no sentido grego do termo). Tanto que se compara a Tântalo, personagem da mitologia que teria traído a confiança dos deuses ao lhes servir carne humana.

Não tentes dissimular! Tua

É a culpa, pobre Tântalo,

Profanaste o sagrado, rompeste

A bela união com orgulho insolente,

Mísero! Quando, repletos de amor, os gênios

Do universo esqueceram-se em ti, pensaste em

Ti mesmo, pobre tolo, e julgaste

Que se aviltando, os benévolos te

Servissem, os Celestes, como servos estúpidos!

Não existe em lugar algum um vingador,

Devo evocar sozinho o escárnio e o anátema

Em minha alma? Ninguém

Além de mim para arrebatar a coroa

Délfica da cabeça, puxando as mechas do cabelo,

Como diria um visionário calvo? - (HÖLDERLIN, 2008, p. 109).

Um elemento estranho neste enredo - e que levantamos como hipótese para o fracasso da tragédia almejada - é este timbre de mea culpa presente neste trecho. É como se Empédocles aceitasse a pecha de ímpio por ter dito 'ser como um deus', o que definitivamente soa estranho considerando seu passado de elevação e comunhão com o sagrado. Um deus que se amortiza por seguir sua vontade, que empalidece diante da realização de sua grandeza, que ressente de seu próprio espírito pode ser o herói de uma tragédia ao modelo grego?

Esta fraqueza subjetiva do personagem acompanha a cena seguinte quando Pausânias, seu discípulo, entra em cena e o consola, isto é, procura lhe convencer de que não cometera nenhum erro ou crime contra os deuses. Diz o fiel amigo: "Nunca é demais ser íntimo, como tu és de todos os deuses do Universo." (HÖLDERLIN, 2008, p. 111). Ambos têm seu diálogo interrompido pela indicação da chegada do grupo que levará a cabo o plano do sacerdote antagonista.

$\mathrm{Na}$ quinta cena do primeiro ato temos o embate direto entre os dois 'personagens motores' da trama: o herói que se elevou a deus e o sacerdote rebaixado a professor de uma fé morta. Neste embate deveríamos encontrar todos os pontos que ligam cada personagem à intriga e esta à sua fatal conclusão. Todavia, o desenvolvimento do conflito não é bem posto e o que temos é uma cena longa, mas com pouca dramaticidade.

Crítias se posiciona logo ao lado de Hermócrates e ambos desdenham do deus com fisionomia triste diante deles. Empédocles responde sem beligerância e clamando apenas não ser atacado. Hermócrates não se dá por satisfeito e incita os três agrigentinos que o acompanhavam a interpelarem o suposto deus-Empédocles. O coro se manifesta individualmente por algumas vezes e sempre julgando o herói como alguém sem crédito. Aproveitando o momento oportuno o sacerdote profere sua excomunhão.

É inútil, não retornas

Ao que é nosso; pois pertences

Aos vingadores, aos deuses santos da morte.

E pobre de quem, a partir de agora, acolher com afeto

Uma tua palavra na alma, 
Quem te cumprimentar e estender-te a mão,

Pobre de ti e de quem conceder-te

Um trago ao meio-dia, ou te admitir

À mesa, e sob seu teto propiciar-te o sono

Brando quando, à noite, bateres à sua

Porta; ou quando morreres, preparar-te

A chama funerária! — Longe de nós!

Os deuses pátrios não mais toleram o sacrílego,

Nos lugares onde se elevam os seus templos. (HÖLDERLIN, 2008, p. 131).

A acusação de impiedade e as palavras condenatórias do destino do personagem principal não suscitam no mesmo nenhuma reação à altura, seja lamentando seja contrariando. Pelo contrário, há certo conformismo entre os desejos do protagonista e do antagonista, pois na mesma cena Empédocles já anuncia, de forma enigmática, que pretende se afastar para morrer sozinho.

Como vedes, de nada vale irritar

Um coração que sangra. Concedei-me

De agora em diante, que siga em silêncio a senda

Da morte santa e silente, senda que transponho.

Desatais da charrua a vítima para ser imolada

E nunca mais o atingirá o aguilhão do condutor. (HÖLDERLIN, 2008, p. 125).

A ênfase das consequências da excomunhão acaba por cair sobre Pausânias que, doído pelo mestre expulso, faz do destino dele o seu, o que desperta a compaixão de Empédocles que implora sem sucesso pela salvação do querido pupilo. E é a recusa de pouparem o discípulo de tal pena que provoca a fúria do herói, o que indica que, no fundo, o personagem trágico desenhado por Hölderlin possui o amor como traço fundamental da alma, mas não um desejo pessoal que, se realizado, provoca o antagonismo das leis, da sociedade e da cultura.

Este traço amoroso de Empédocles é reforçado na cena seguinte quando, pedindo para falar a sós com o rei Crítias, o personagem, prestes a ser expulsa de sua cidade natal, novamente se preocupa mais com outra pessoa do que consigo, no caso, com a filha do monarca, a jovem Panteia.

\section{A peça $-2^{a}$ versão}

A segunda versão traz algumas novidades na redação do texto. O coro está presente nesta primeira cena do primeiro ato, apesar de a distância e sem discurso direto. O rei Crítias é substituído por outro monarca, Mécades, e este inicia a peça junto a Hermócrates em clara confabulação contra o filósofo.

Empédocles é referido por ambos como inimigo a ser derrotado, causador de tumulto entre o povo graças à sua terrível fala de 'ser como um deus'. Isto nos indica uma reformulação no papel do antagonista. Se na primeira versão este papel era exclusivo ao sacerdote - com o rei Crítias em seu apoio, contudo, sem motivos profundos para destruir o herói - agora Mécades é um aliado declarado do arconte.

Em suas confabulações, ambos sabem que Empédocles está fragilizado desde que o povo reagiu com estranheza e suspeita à sua auto declaração divina. A confusão da vida citadina da versão anterior se repete aqui, com a diferença de que agora rei e sacerdote estão firmes na resolução de expulsar e até assassinar o filósofo se for preciso.

Há pouca diferença entre o texto teatral das duas versões. O teor poético mantém-se próximo do 
já visto, e as indicações cênicas restringem-se ao final da cena para saída e entrada de personagens. Contudo, talvez haja uma maior aproximação da personagem principal com a personagem histórica, isto é, do Empédocles personagem para o pré-socrático de Agrigento.

Em um determinado ponto do diálogo Mécades admite ter escutado parte do discurso do pensador na ágora, e o repete parcialmente para Hermócrates. Desta longa citação, que abaixo reservamos apenas uma pequena parte, é perfeitamente possível relacionar com a doutrina dos quatro elementos e com a cosmologia do Empédocles histórico.

E vivem sol, ar, terra e seus filhos

Estranhos um ao lado do outro, Sós, como se não se pertencessem.

(...)

No espírito divino

As forças livres e imortais do mundo

Movem-se, sempre vigorosas.

(...) Em mim

Os mortais e os deuses trocam

Força e alma, tornando-se Um.

E com mais calor as forças eternas abraçam

O coração anelante e crescem mais fortes

Os homens sensíveis de espírito liberto. (HÖLDERLIN, 2008, p. 251-2).

A segunda cena repete aquela terceira da primeira versão na qual Empédocles sozinho lastima sua desgraça de ter perdido o contato íntimo com a 'Natureza'. Inclusive o autor deliberadamente aproveita alguns versos para esta nova redação da peça. A terceira cena também repete a quarta anterior na qual Pausânias consola o triste Empédocles. A diferença aqui são duas. A primeira é que o texto termina sem um fim adequado, indicando abandono da redação. E a segunda é que Empédocles está mais amargurado, mais convicto de sua própria queda, chegando até a escarnecer de si mesmo.

O que seria do céu, do mar

Das ilhas e estrelas, de tudo o que se

Descortina ante os olhos dos homens, o que seria

Desta cítara calada, se eu não lhe infundisse

Som, alma e palavras? O que seriam

Os deuses e seu espírito, se eu não os

Proclamasse? (HÖLDERLIN, 2008, p. 279).

Infelizmente não foi somente esta cena a ter sua redação interrompida nesta segunda versão da peça. Depois desta cena o texto continua com uma fissura na estrutura que deveria ter cinco atos e passa para um diálogo entre Panteia e Delia que deveria ser o final do segundo ato. A história aqui já está bem avançada e narra a breve conversa entre as duas moças antes de se encontrarem com Pausânias que vinha descendo o Monte Etna.

Ou seja, boa parte daquilo que foi produzido na primeira versão aparece aqui implícito: Empédocles é expulso de sua cidade natal e Pausânias o acompanha. Dirigem-se para a região do vulcão e buscam abrigo em vão. Empédocles se afasta de Pausânias com a promessa de simplesmente caminhar e se lança ao ventre ígneo.

Após isto ocorre o último diálogo da última cena desta segunda versão entre os três admiradores 
do mago (Pausânias, Panteia e Délia) que ainda não sabem da morte do mestre.

\section{A peça $-3^{a}$ versão}

A terceira versão da peça é tão curta quanto a segunda, porém apresenta mudanças de roteiro mais drásticas. A primeira cena começa com a didascália de que Empédocles está sozinho e despertando. Seu ânimo é positivo, alegre, como o de uma pessoa que passou por uma tormenta que não voltará. De fato, pelo texto descobrimos que esta primeira cena ocorre após a expulsão do herói. Ou seja, ele já está vivendo no Etna uma nova vida, sem a perturbação dos cidadãos e de seus representantes malignos.

O personagem está aqui em plena sintonia com aquelas 'forças da Natureza' das quais ele, nas outras versões, sentia-se distante e abandonado. A sintonia com o Éter dá-lhe todas as sensações e graças reservadas aos deuses - sim, Empédocles vive como um deus ali - e sua união com o divino só não é maior porque ainda não se juntou completamente à montanha de fogo. Este plano já está formado em sua mente, todavia, com a aproximação de Pausânias, Empédocles recolhe as palavras que revelariam ao discípulo sua vontade.

Na segunda cena discípulo e mestre dialogam tranquilos. O pior já passou para os dois e Pausânias acaba de encontrar numa parte mais alta do monte uma caverna com excelentes condições para habitarem em refúgio de corpo e espírito. Todavia, Empédocles procura proteger o pupilo sem revelar-lhe o plano final. Daí busca dissuadi-lo a se afastar, a valorizar sua juventude e deixar que ele, o mestre, adote para si a regra que rege todo o Universo.

Tens de saber: eu não sou teu

Nem tu és meu; e a tua senda não

É a minha; meu futuro floresce noutra parte.

Este pensamento não é de hoje,

Já estava decidido desde meu nascimento.

Ergue os olhos e ousa! O Uno se

Fragmenta, o amor não morre em seu botão

E por toda a parte a árvore esvoaçante

Da vida se ramifica em livre alegria.

Nenhum vínculo temporal permanece o mesmo;

Devemos separar-nos, filho!

Não hesites! Não detenhas meu destino! (HÖLDERLIN, 2008, p. 311).

Entretanto Pausânias não se dá a contento. Depois que passara a dor de ser expulso e vilipendiado por sua pátria e amigos, por que afinal agora, em paz na montanha, abandonaria o mestre? "O que eu, o que eu te fiz? (...) [Por que] teu coração se alegra esforçando-se em livrar-se do único e derradeiro amigo?” (HÖLDERLIN, 2008, p. 313).

Apesar do impasse entre os dois Empédocles está decidido a cumprir sua vontade e incumbe o aprendiz a realizar uma viagem a outra região da Itália, onde poderia encontrar pessoas amigas e aprender com elas. A cena termina com a indicação cênica do afastamento de Pausânias.

A terceira e última cena desta versão é o encontro entre Empédocles e o egípcio Manes. Este personagem inédito na trama parece representar algum tipo de sabedoria divina semelhante a Empédocles. Manes é também um homem tocado pela divindade e a chance do diálogo entre ambos é, para o público, o efeito de ver o herói no espelho. Empédocles tem em Manes alguém que entende sua natureza divina e, 
se explicar para ele é, por extensão, se refletir para o espectador. Todavia, a redação chega a seu fim.

\section{Ponderações sobre o insucesso}

Hölderlin esteve no centro do Romantismo, do Classicismo e do Idealismo sem, contudo, se identificar plenamente com nenhum deles. Sua veia poética originalíssima transitou e participou de várias noções estéticas sem, todavia, ser absorvida por nenhuma delas. Sendo assim, existem mais de uma forma para avaliarmos quais teriam sido os propósitos originais dele ao escrever a peça teatral em tela e porque teria fracassado em finalizá-la.

Segundo Marco Aurélio Werle (2015), Hölderlin levou para o teatro a mesma missão que Hegel levou para a filosofia, a saber, afirmar o idealismo como expressão mais elevada do espírito humano. $\mathrm{O}$ drama de Empédocles entre a natureza divina e a religiosidade estática, entre a sabedoria elevada e o senso comum, entre o eu e seu tempo seriam expressões do conflito da própria Filosofia dividida entre o Idealismo e o senso comum moderno.

Entretanto, diferente daquele filósofo da "Fenomenologia do Espírito" (1807), Hölderlin não alimentou uma concepção na qual a consciência gradualmente retomaria na Cultura a unidade perdida com a Natureza. Esta visão otimista sobre a Modernidade na qual o espírito do povo ou da nação encontraria o Ideal em sua produção histórica e concreta, superando o espírito de cisão da técnica fria e da ciência abstrata - Hölderlin já a havia manifestado no livro anterior à peça sobre Empédocles, o romance "Hipérion" (1797). O tom de seu pensamento no momento das redações é de pessimismo e de tragedicidade.

Embora resulte de considerações de ordem poetológicas sobre o trágico como conflito entre arte e natureza, entre a história e o homem, a tragédia que, na verdade, não foi concluída, apresenta em sua base um dilema concernente ao destino do idealismo, quanto à própria legitimidade do saber filosófico ideal e da possibilidade de conseguir impor-se diante da existência e das exigências da finitude. Esse "drama” pode ser verificado na origem dos planos poéticos de Hölderlin, para o que viria a ser A morte de Empédocles, já esboçados em 1794, após a concepção inicial do Hipérion, na época ainda um fragmento. (WERLE, 2015, p. 319).

Por viés diferente de Werle e da Filosofia, Gonçal Mayos (1992) procura encontrar na estética do Romantismo as motivações originárias de Hölderlin para a composição da peça. Este movimento artístico foi compreendido em suas linhas gerais como portador dos valores do indivíduo radicado em si, da subjetividade isolada da comunidade, da solitária genialidade que intuiria divinamente o Belo e o plasmaria sem intermediários na Arte. Neste sentido, são condizentes os pensamentos generalistas que veem em todos os românticos a tendência de desprezar as causas coletivas e de defender o apolitismo.

Entretanto Mayos segue na direção contrária a esta generalização e defende que, com Hölderlin, temos um projeto artístico fraterno-político. Resgatando a noção platônica de enthousiasmós, isto é, possessão ou inspiração divina da alma do artista, Mayos diz que

Somente neste momento afortunado do entusiasmo o homem é plenamente ele e, ao mesmo tempo, supera-se a si mesmo para realizar o ideal de si: o divino, o infinito. Por isso, também para Hölderlin (como para Giordano Bruno) o entusiasmo é um "furor heroico" que leva o homem a superar-se no divino e, paradoxalmente, a encontrar-se a si e ao cosmos único e total no divino. O momento do entusiasmo é um momento de reconciliação, de plenitude, de apoteose e êxtase, que se dá sempre no ponto de partida. (MAYOS, 1992, p. 57). 
Sendo assim, a almejada união entre os homens advirá quando todos os homens forem possuídos pelo entusiasmo e encontrarem a si mesmos em seus enthousiasmós. Temos aqui uma volta para dentro de si que forma a comunidade de iluminados naquilo e por aquilo que lhes é universal e superior: o deus interior.

Logo, de acordo com a perspectiva acima, Hölderlin não acredita na política como derivada das luzes da razão nem do retorno à unidade idílica perdida. Menos ainda o poeta abandona o outro e se radica em solidão criadora. A construção fraterno-política é coletiva e obra da experiência poético-divina de todos os homens ao se identificarem naquilo que Platão considerou, no Ion e no Fedro, ser a perda de si vivida pelo poeta em seu frenesi.

A primeira versão da peça concentra inegável beleza estética nos seus versos com pouca dramaticidade em sua trama. Como apontamos acima, Empédocles parece resignado diante da cisão que o mantém anátema de seu tempo. Seu conformismo indica que possui consciência das condições insuperáveis de reconciliação, o que o põe em posição de compaixão até mesmo para com seus algozes, como demonstra com o rei Crítias.

Sem esta contradição entre a liberdade subjetiva e a potência objetiva, o embate entre o Belo ou o Ideal e a pobreza da vida humana não pode ter lugar. Há simplesmente total desequilíbrio entre ambos. O personagem decide morrer sem conflito, o que imobiliza a dialética ascendente da liberdade humana justaposta à precariedade das formas mundanas.

Um dos grandes erros dramáticos de Hölderlin é-nos explicitado por Theo Machado Fellows (2011). Concordando com ele, falta a Empédocles a transgressão à ordem dos deuses. Em outras palavras, a história do personagem principal não incorre em nenhuma býbris, em qualquer desmedida que gere um entrelaçamento entre a ordem divina e a ordem natural e exija, por sua vez, o expurgo do excesso, a correção da rota, o reestabelecimento da harmonia perdida.

O crime imputado a Empédocles na trama não possui este vigor dramático. O fato de Pausânias reiteradamente diminuir a gravidade da auto imputação divina por seu mestre, de Panteia continuamente devotar-lhe admiração irrestrita e, também, a reação mesquinha dos agrigentinos e de seus líderes não alcançam e até mesmo diminuem a gravidade da suposta falta.

[...] esta culpa, que naturalmente pode ser entendida como a hýbris grega (ou o nefas latino, expressão que o próprio Hölderlin chega a utilizar em alguns textos), é a decorrência da ação da liberdade humana que se contrapõe aos deuses e, a partir da falta, afirma a liberdade humana por sua própria perda. Empédocles não é, no entanto, em nenhum momento apresentado como este homem decaído por uma falta qualquer. Talvez a nota de Hölderlin sobre a falta original queira precisamente dizer que esta falta está subentendida por sua condição humana, mas isto não é suficiente para que a ação dramática se desenvolva. (FELLOWS, 2011, p. 245).

A segunda versão da peça é mais centrada na figura do personagem principal e tenta abrir mão dos elementos secundários da primeira sem, todavia, mudar o essencial. Dentre as mudanças ocorridas temos a ausência dos conflitos diretos entre prota- e antagonista, assim como com o coro de cidadãos. Isto indica que a decisão de se jogar no vulcão torna-se mais pessoal, como se fosse expressão de uma necessidade interna da personagem.

Então poderíamos especular pelo menos três motivos para este desejo profundo de se desligar da vida e retornar ao seio dos deuses. O primeiro, já vimos, é o idealista. A auto aniquilação da personagem a partir de uma necessidade interna representaria o mais elevado grau de exigência da razão que conhece a si 
e sabe de sua essência divina ao mesmo tempo em que abre mão de tudo o que é contingente e supérfluo. O segundo motivo, também o vimos, seria o romântico. Se a construção de um mundo mais belo e familiar está fechada coletivamente até que todos estejam a par de sua divindade, a saída mais nobre e a mais adequada é abrir mão da própria vida num ato de elevação e abandono do inferior.

E "neste ponto entra em cena um terceiro motivo do Empédocles, que é de ordem política: o sacrifício heroico do indivíduo pelos ideais mais elevados, no contexto de desdobramentos da Revolução Francesa" (WERLE, 2015, p. 322). Esta perspectiva não deixa de ter sua validade enquanto chave de leitura da obra e está de acordo com a visão consensual que a historiografia das ideias tem do poeta suábio.

Pelos elementos que viemos elencando chegamos à conclusão que o enredo da peça não atende às exigências da tragédia clássica porque o herói não respeita as contradições inerentes entre o humano e o divino. Empédocles quer se fazer absoluto sem sofrer a ambiguidade de sua própria condição e, neste sentido, a personagem é mais um poeta do que um herói trágico. Aquela unidade plena (seja com a Natureza, a História, o Destino ou os Deuses) é permitida apenas em um vislumbre, um lampejo de elevação cósmica antes do fim terrível - entretanto, Empédocles quer gozá-la em sereno abandono da vida e união com o vulcão.

Hölderlin não consegue efetivar Empédocles como herói trágico porque ele não consegue escapar da aceitação de sua própria finitude. Sua morte, que o autor desejava apresentar como unificação com o divino, o retorno para a "sobriedade natural", na verdade aparece como uma fraqueza diante da natureza do trágico, na medida em que não aceita a própria realidade em suas eternas oposições. (...)Em outras tragédias o herói luta em meio às contraposições e aparenta solucioná-las, mas na verdade entra em decadência ao perceber que a resolução do conflito é meramente superficial e transitória. Nisso consiste a grandiosidade do trágico: no herói que passa repentinamente da fortuna ao infortúnio. (COSTA, 2007, p. 50).

Finalizamos reconhecendo a importância de Hölderlin acima de tudo como poeta. Os versos da peça compensam em beleza e arte o que lhe falta de teatralidade. Se por um lado lhe faltou a composição exata da tragédia, por outro lado lhe sobraram o talento e a contribuição para a recepção deste gênero na modernidade.

\section{Referências}

COSTA, Solange Aparecida de Campos. (2007). Aspectos do trágico em Hölderlin. 138 f. Orientador Paulo Soethe. Dissertação (Mestrado em Estudos Literários) - UFPR, Curitiba. Disponível em: < https://acervodigital.ufpr.br/bitstream/handle/1884/18149/SOLANGE-Hölderlin-Dissertacao__Copia1.pdf?sequence=1\&isAllowed=y>. Acesso em 13/08/2019.

FELLOWS, Theo Machado. (2011). “A morte de Empédocles de Hölderlin: A tragédia como obra filosófica”. In: Kínesis. Revista de Estudos dos Pós-Graduandos em Filosofia da Universidade Estadual Paulista. Marília, v. III, $\mathrm{n}^{\circ}$ 05, julho, p. 240-25.

HÖLDERLIN, Friedrich. (1797-1800). A morte de Empédocles. Tradução e estudo Marise Moassab Curioni. São Paulo: Iluminuras, 2008.

MAYOS, Gonçal. (1992). "Hölderlin, un proyecto emancipatorio fracassado". In: Convivium. Revista de Filosofía, Barcelona. Segunda Série, n. 3, p. 53-74. Tradução de Gabriel Lago de Sousa Barroso. Disponível em: < http://www.ub.edu/histofilosofia/gmayos_old/P DF/H\%F6lderlinPort.pdf>. Acessso em 13/08/2019. 
WERLE, Marco Aurélio. (2015). "Hölderlin e Hegel: a afirmação trágica e filosófica do idealismo". In: 0 que nos faz pensar. Cadernos do Departamento de Filosofia da PUC-Rio. Rio de Janeiro, $\mathrm{n}^{\circ}$ 36, março.

Artigo recebido em: 12 de janeiro de 2020

Artigo aceito em: 23 de fevereiro de 2020 